\title{
Analisando o processo criativo do desenvolvimento de um projeto de resgate tipográfico
}

\section{Analyzing the creative process of developing a type revival project}

Danielly Lourenço das Chagas, Josinaldo Barbosa da Silva, Eduardo A. B. M. Souza

resgate tipográfico, processo criativo, processo de design

Acompanhamos o desenvolvimento de uma fonte digital por meio do resgate de uma tipografia impressa no livro La Geografia do século 16, do acervo da Biblioteca do Instituto Ricardo Brennand. Na pesquisa, analisamos o processo criativo: tomada de decisões, acasos e a deliberação do desenho dos tipos. Isso foi feito por meio da observação participativa, incluindo o acompanhamento das discussões de trabalho: o foco da observação foram os impasses, dúvidas, sugestões e encaminhamentos. Como resultado, mapeamos o desenvolvimento da fonte e identificamos etapas que necessitam de mais atenção, fatores que poderiam auxiliar na resolução dos problemas, atuação das pessoas e de elementos externos, ou mesmo acasos. Esse relato atesta que o desenvolvimento de uma fonte tipográfica não pode ser compreendido por regras estabelecidas em metodologias, já que é um processo complexo e altamente dependente do contexto.

typographic revival, creative process, design process

We followed the development of a digital font through a typographic revival from print type in the $16^{\text {th }}$ century book La Geografia, from Instituto Ricardo Brennand's library. During this research, we analyzed this creative process: decision-making, accidents and deliberation in typefaces. This was done through active observation, including taking part in discussions: we focused in observing obstacles, doubts, suggestions and choices. As result, we mapped the font development and identified stages that need more attention, points that could aid in problem-solving, people's and external elements' roles and even chance. This report shows that developing a font cannot be comprised in rules from methodologies, but is rather a complex process, highly context-dependent.

\section{Introdução}

O desenvolvimento tipográfico no Brasil tem como características predominantes a produção de fontes displays e fantasias baseadas no regionalismo e experimentações. Nesse cenário, é imprescindível destacar "as iniciativas de movimentação e incentivo à produção tipográfica em âmbito acadêmico" (M. Silva \& J. Silva, 2011), responsável por quase toda a produção de fontes digitais na época.

Esse aumento na produção nacional é acompanhado também por publicações acadêmicas sobre o assunto. No entanto, a maioria dos trabalhos são relatos do uso de métodos como a adaptação do mapa de derivação de Adams (1989 como citado em Farias, 2001, p.39), o 
sistema de modulação da fonte e o método de espacejamento. Segundo Necyk \& Ferreira (2010 como citado em Cavalcanti, 2014), a principal causa dessa ausência é a valorização do resultado em detrimento do processo.

Dessa forma, este artigo tem como proposta analisar o processo criativo do desenvolvimento de uma fonte - um projeto de resgate tipográfico - observando o processo de decisão, os percalços, métodos, abordagens projetuais e influências.

\section{Referencial teórico e metodologia}

Para compreender o processo criativo da fonte, utilizamos o modelo de estudo desenvolvido por Wallas (1926, citado em Lubart, 2007) e complementado por outros autores, também citados por Lubart. (Figura 1).

Figura 1: Etapas do processo criativo

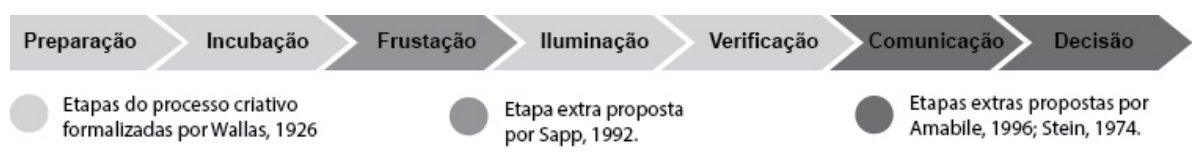

Fonte: Elaborado pelos autores a partir de LUBART (2007), capítulo 6.

Para a análise das etapas do desenvolvimento da tipografia, utilizamos a proposta de Cheng (2005), apresentado na Figura 2. Esse esquema é complementado, em algumas das etapas, por elementos como o mapa de derivação dos caracteres (1989 como citado em Farias, 2001, p.39), proporções métricas dos caracteres (Buggy, 2007; Ribagorda Paniagua, 2009) e de modulação (Reis, 2011).

Figura 2: Processo geral de criação de fonte

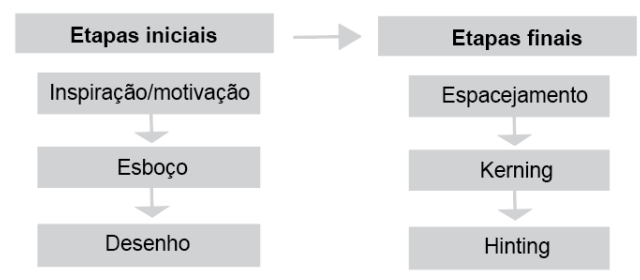

Fonte: Elaborado pelos autores a partir de CHENG (2005, pg 8-9).

Cheng (2005) afirma que cada projeto é único, pois dependem dos interesses dos designers e de suas especificidades. Todavia, Mandel (2011) aponta que durante o início do trabalho devemos responder duas perguntas fundamentais: "porquê" - qual a problemática a ser resolvida, e quais finalidades a fonte exercerá; e, "para quem" — qual o público do projeto. Para essas e outras perguntas, utilizamos como método de pesquisa a observação participativa e entrevistas com a equipe que desenvolveu a fonte. 
Portanto, nossa análise identificou as etapas do processo criativo conforme o esquema da Figura 1, considerando também os eventos específicos ocorridos durante o desenvolvimento do projeto.

\section{Discussão}

Segundo Cheng (2005), a primeira etapa do processo de desenvolvimento de fontes está relacionada com o seu motivo, que pode ser de caráter pessoal. Nesse sentido, o projeto em questão justifica-se na continuidade de uma pesquisa anterior por meio de um novo estudo sobre o livro La Geografia de 1564, do acervo da Biblioteca do Instituto Ricardo Brennand.

A primeira etapa do processo criativo é relacionada à Preparação (formulação/organização e a busca de informações sobre o problema). Para melhor organização, podemos dividi-la em duas partes. Na parte $\mathrm{A}$, temos a definição do problema, relacionada com a inspiração e as motivações do projeto. Já a parte $\mathrm{B}$ corresponde à busca de informação, caracterizada aqui pela pesquisa bibliográfica e de referências visuais.

É interessante notar que essa etapa, mesmo caracterizada como inicial, também aconteceu posteriormente, pela necessidade de imagens com melhor resolução. Além disso, a preparação ocorreu de forma concomitante com a seleção de caracteres, que pode ser compreendida como uma parte da etapa de Incubação. Também ajudou a resolver questões específicas, como a definição dos terminais da fonte. Ou seja, há recorrência da preparação ao longo do processo, com novas leituras sobre resgate tipográfico, pesquisas de referências de tipografias do século 16 e sobre os softwares para desenvolvimento de fontes digitais.

Os problemas no desenvolvimento - tais como a definição de terminais, diferenças de angulação no itálico e a própria condição colocada de afastamento e de orientações remotas levaram à etapa de Frustação e estagnaram o projeto. No entanto, após esse momento, ocorre uma nova etapa, que consideramos um período de Incubação e lluminação, em que surgiram sugestões de soluções para os problemas, tais como:

- definição e uniformização dos terminais e serifas dos caracteres.

- a inclinação dos caracteres segundo o impresso no livro.

- utilização de outra fonte do mesmo período como referência.

- decisões estéticas e fidelidade formal com os tipos originais

- elaboração de caracteres ausentes

Como exemplo elucidativo, apontamos que diante do problema da definição dos terminais, identificamos as etapas de Frustração, Incubação e Iluminação. Embora nem sempre pudessem ser claramente delineadas ou ocorrerem nessa sequência, elas eram definidas por suas características: dificuldade e frustação diante do problema, sugestões de soluções e aperfeiçoamento do projeto.

Assim, as sugestões foram analisadas, discutidas e testadas para tomar as decisões. A partir daí, o projeto seguiu para a complementação dos desenhos dos caracteres e ajustes 
de suas formas finais; já executada no software específico. Depois disso, ocorre a etapa de verificação, caracterizada por testes da eficácia e possíveis reparos.

Com os caracteres finalizados, começa a segunda parte da finalização da fonte, o espacejamento. Primeiro, foi testado o uso da média das medidas dos espacejamentos dos caracteres impressos no livro, mas não apresentavam regularidade. Assim, foi descartado. Utilizou-se então o método de Walter Tracy (2003) e para kerning, a lista dos pares de caracteres indicados por Cheng (2005) e testes de impressões da própria fonte.

A etapa de comunicação é caracterizada pela de inserção da ideia na esfera social, ou a testagem do produto na sociedade com o objetivo de analisar a utilidade da ideia (Amabile, 1972; Stein, 1974 como citado em Lubart, 2007). Ela ainda não foi realizada, pois a realização até aqui consta do desenvolvimento das caixas-baixas, números e sinais diacríticos e de pontuação para a língua portuguesa.

A última etapa do processo criativo é a de decisão, que tem como princípio deliberar de acordo com os resultados das etapas de verificação e comunicação. De acordo com Lubart (2007), o indivíduo pode concluir o projeto ao alcançar o ponto desejado ou por ter sido um fiasco. Neste caso, o projeto teve seu objetivo alcançado, mas não foi finalizado: a complementação do set tipográfico e o hinting será realizado posteriormente.

O processo de esboço/desenho e a etapa de finalização (espacejamento e kerning) podem ser resumidos pela figura 3 :

figura 3: Etapa de esboço/desenho do desenvolvimento da fonte de resgate tipográfico.

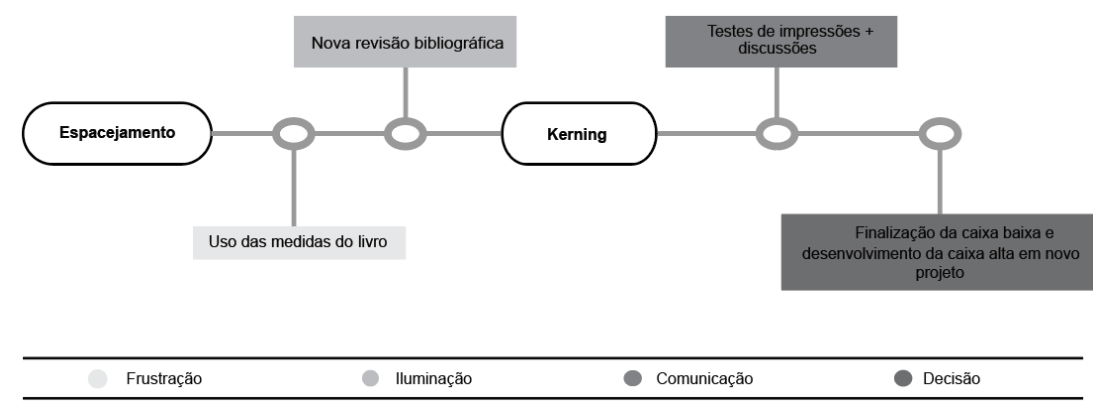

Fonte: Elaborado pelos autores.

Esquema 5: Etapas de Espacejamento e Kerning do desenvolvimento da fonte de resgate tipográfico.

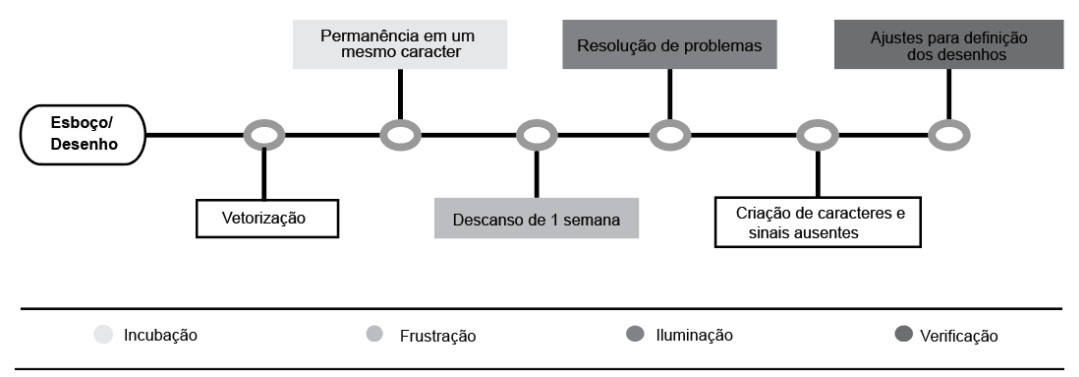

Fonte: Elaborado pelos autores 


\section{Conclusão}

Nossas observações apontam que tanto o processo criativo quanto o esquema metodológico não decorrem uniforme e linearmente, como apontam Lubart (2007) e Cheng (2005), respectivamente. As etapas podem ocorrer concomitantemente e, em geral, são de difícil delineamento. Salientamos aqui que o método de Cheng (op. Cit.) para o desenvolvimento da fonte, não foi citado pelo grupo que desenvolveu a fonte: foi apenas uma ferramenta exclusiva dessa pesquisa para identificação das etapas de desenvolvimento. Ainda assim, vimos que as etapas existem e podem ser adequadas ao esquema do processo criativo, considerando que há indefinições e especificidades na prática projetual.

Quanto às decisões, constatamos que elas são tomadas diante de cada resultado, baseadas em testes ou mesmo de forma opinativa. A definição ocorre diante do resultado formal apresentado, assim como os problemas e suas soluções.

De maneira geral, podemos dizer que o modelo de processo criativo (figura 1) e o modelo de Cheng (2005) mostraram-se efetivo para a análise. Todavia, sua representação não corresponde exatamente à realização do processo criativo. Como dito, as etapas nem sempre ocorrem na sequência e de maneira bem definida. Além disso, mesmo que o projeto tenha parâmetros bem definidos e limitados - como um projeto de resgate tipográfico -, verificamos que várias de suas decisões e encaminhamentos ocorrem de forma intuitiva e seguem um modelo que poderíamos caracterizar como problema-solução e encaminhamentos até a solução final.

\section{Agradecimento}

A Biblioteca José Antônio Gonsalves de Mello, do Instituto Ricardo Brennand por possibilitar o acesso ao material pesquisado.

Ao IFPE campus Recife por todo apoio a realização da pesquisa.

\section{Referências}

Blauth, Lurdi (2019). Pesquisa em arte: acasos e permanências de um processo gráfico. Recuperado em 14 de novembro, 2019, de http://www.iconica.com.br/arteacaso/artigos/lurdi_blauth.html.

Buggy, Leonardo. (2007). O MECOTipo: Método de Ensino de Desenho Coletivo de Caracteres Tipográficos (1a ed.). Recife:Buggy.

Cavalcanti, Aline S. (2010). Hidromel: uma tipografia digital com raízes litográficas. Trabalho de Conclusão de Curso, Universidade Federal de Pernambuco, Recife, Brasil.

Cavalcanti, Aline S. (2014). Design de tipos em Pernambuco: estudo de uma situação de ensino. Dissertação de Mestrado, Universidade Federal de Pernambuco, Recife, Brasil.

Cheng, Karen (2005). Designing Type. New Haven: Yale University Press. 
Farias, P. (2001). Tipografia Digital: o impacto das novas tecnologias. 3. Ed. Rio de Janeiro: $2 A B$.

Lebedenco, Érico (2019). Resgate tipográfico: delimitações, características e prática no design de tipo. Dissertação de Mestrado, Universidade Anhembi Morumbi, São Paulo, São Paulo, Brasil.

Lubart, Todd (2007). Psicologia da Criatividade. Porto Alegre: Artmed.

Mandel, Ladislas (2011). O poder da escrita. São Paulo: Rosari.

Reis. Pedrina T. (2011). Azeitonas: de letreiramento litográfico a fonte digital. Trabalho de Conclusão de Curso de Graduação, Universidade Federal de Pernambuco, Recife, Brasil.

Ribagorda Paniagua, José María (2015). Ibarra Real. Un modelo metodológico para el redibujo y reconstrucción de tipografías clásicas.Del plomo al vector. Tese de Doutorado, Universidad Complutense de Madrid, Madrid, Espanha.

Silva, Michelly P., \& Silva, Josinaldo B. (2011). Geração de tipografias através de processos experimentais. Recuperado em 3 de maio, 2020, de https://www.academia.edu/1704488/gera\%c3\%87\%c3\%83o_de_tipografias_atrav\%c3\%89s _de_processos_experimentais.

Tracy, Walter (2003). Letters of Credit: A view of type design. Boston: D.R. Godine.

\section{Sobre os autores}

Danielly Lourenço das Chagas, graduada, Brasil <danychagas2015@gmail.com> Josinaldo Barbosa da Silva, Dr., IFPE, Brasil <josinaldobarbosa@recife.ifpe.edu.br> Eduardo A. B. M. Souza, M.e., IFPE, Brasil < eduardosouza@recife.ifpe.edu.br> 